\title{
Exploration of Enterprise Oriented Application Oriented Information Technology Talents Training
}

\author{
Kai Xiong, Kai Mao, Xuanchang Zhou \\ The City College of Zhejiang University \\ Hangzhou, China \\ xiongk@zucc.edu.cn
}

\begin{abstract}
This paper introduces the characteristics and specific implementation process of enterprise orientation in the training of applied information technology talents. This paper analyzes the influence of two aspects of undergraduate teaching and college students' scientific research on the effect of talent training, and puts forward the corresponding solutions. Through examples, this paper proves the outstanding advantages of the enterprise oriented model in the training of information talents, and lays the foundation for the subsequent research.
\end{abstract}

Keywords-Enterprise orientation; Information technology; Applied undergraduatestyle; Education

\section{INTRODUCTION}

With the development of society and economy, university education has entered a new stage. The rapid development of application-oriented universities has greatly complied with the demand for talent diversification from elite education to popular education in China's higher education. The aim of application oriented university is to train advanced applied talents with solid theoretical foundation and skilled practical ability. In the application oriented university education, we must adhere to the guiding position of practice, that is to say, the ultimate goal of most talents training is to be used by enterprises [1]. Therefore, the article is to explore the enterprise oriented to reverse the reform of personnel training mode of higher education. The so-called enterprise oriented, that is to say, the innovation and development of education, starting from the needs of the enterprise, grasp the pulse of the times, the starting point and destination point on the train to the social and practical talents, so as to promote education and competition. It is not difficult to imagine that education is out of line with the market or lags behind the market and enterprises, and the trained talents can not meet the needs of the market and enterprises, and adapt to the development of the times. In order to develop the applied university education with the enterprise orientation and conform to the tide of the times, the education potential can be turned into productivity, and finally the purpose of promoting the development of education can be achieved [2].

At the same time, we also have access to the information society, information technology is a comprehensive and practical subject, requires high practice skills, therefore, the application of information technology personnel training as an example, has important theoretical and practical significance on the construction of application oriented practice teaching system [3]. Therefore, I have made some explorations in the cultivation of applied information technology talents, which are oriented by enterprises, and include two aspects of undergraduate teaching and college students' scientific research

\section{THE EXPLORATION OF ENTERPRISE ORIENTATION IN TEACHING}

\section{A. Selecting a Template The Necessity of Enterprise Oriented Teaching Reform}

At present, many colleges and universities will also "school enterprise cooperation" the introduction of the course, some courses are entrusted to the order form "training", the "school enterprise counterparts" is for universities to realize the "employment oriented" provides the guarantee, but the future development of students width, lack of flexibility, but also enable the students to face the the risk of the employer's human resources demand change brings. Therefore, only "school enterprise cooperation" can not fully meet the needs of enterprises and students. We can teach from professional courses or lectures to solve these bottlenecks, allowing students in the specific teaching system in personal training moderate arrangement plan, has the enterprise demand, reform the teaching form and teaching contents of project. Specific ideas: application of connectionist theory study and engineering practice; cultivate the students' practical optical communication line connection and debugging and measurement ability; cultivate students' ability of comprehensive design and innovative thinking; encourage students to take the initiative to contact the business, understand the business needs, take enterprise project into Extracurricular class; training students' team cooperation ability.

\section{B. Enterprise Oriented Curriculum Reform with Optical Communication Technology as an Example}

Optical communication technology and communication engineering experiment is a limited selection of courses, the traditional teaching of the course, commonly used methods at home and abroad in the traditional teaching mode, that is to carry out the verification experiment in the specific test box, the way to cultivate students' ability of independent design and comprehensive experimental ability appear, in view of this situation, at present, do some reforms, reduce part of the 
verification experiment, comprehensive experiment project, to design comprehensive training students and practical ability, but the development is still with the needs of enterprises out of touch, so that students can be very good with the employment. Therefore, this project will be based on the needs of enterprises as the guidance, reform teaching contents and scheme, appropriate to increase the actual project autonomy, integrated enterprise, and emphasizes the importance of active thinking and training ability, passive learning state, improve the comprehensive professional ability to change students' experimental and practical problem solving skills, enhance the professional skill of experiment students. Enterprise oriented to mobilize students' active learning ability, increase interest in learning and practice ability. Therefore, it is of great significance to carry out the research and Exploration on the reform of teaching content and mode based on enterprise demand.

\section{Specific curriculum reform measures}

The reform of the construction of this project mainly focus on the teaching content to complete, and increase enterprise related projects in the teaching content, and mobilize the teachers and students contact with enterprises, at the same time to the needs of the enterprise oriented to complete the comprehensive experimental project design, promote team cooperation, and make reasonable evaluation on performance.

- The content of the present teaching students to collect opinions and suggestions, investigation of students in teaching methods have been carried out on the set of curriculum content to grasp the situation, prepare for the study on Reform of teaching content of the course is a reasonable way to improve.

- Teacher and enterprise contact, discuss the reform method of teaching content. Combined with the traditional verification experiments are difficult to design, reasonable, embodies the comprehensive knowledge of curriculum modules comprehensive design project, and put forward the performance index of the system reflects the requirement of the realization of the design problem as much as possible show with audible, visible taste characteristics, to stimulate students' interest in experiment. The system design project on the independent design and comprehensive student choice making experiment to replace the traditional discrete to the function module for the unit, the experiment content, to cultivate the independent design, the creative thinking of the students comprehensive ability.

On the basis of traditional experiments, the optical communication system design software OptiSystem is introduced, which enables students to directly use the practical software in the optical communication industry. OptiSystem is an innovative optical communication system simulation software package, it sets the design, testing and optimization of various types of broadband optical network physical layer virtual optical connection and other functions in a long distance from the communication system to the LANS and MANS can be used [4]. Meeting the needs of a rapidly developing optical communications market for a powerful and easy to use optical communication system design tool. Related enterprises have huge demand for talents in this field [5].

On the basis of skilled use of the software, a comprehensive experiment "design of grating dispersion compensation communication system based on OptiSystem" is designed. In optical fiber communication system, due to the different frequency components and the transmission speed of each mode component, the signal will form dispersion after a distance of optical fiber transmission, which limits the transmission capacity and transmission quality of the optical fiber. In order to reduce the influence of dispersion, in addition to the traditional narrow spectral source and low dispersion fiber method, the more is the use of appropriate dispersion components to compensate for nonlinear optical method. The main dispersion compensation methods include: fiber type, fiber Prague grating type, FP resonant cavity type, phase conjugate type, light source pre chirp technology. Students can design a simple grating dispersion compensation system by using OptiSystem simulation software, the transmission rate of the system is $40 \mathrm{~GB} / \mathrm{s}$, the working wavelength of $1550 \mathrm{~nm}$, $50 \mathrm{~km}$ long fiber, fiber attenuation coefficient is $0.2 \mathrm{~dB} / \mathrm{km}$, the optical fiber dispersion coefficient is $16 \mathrm{ps} / \mathrm{nm} . \mathrm{km}$. The screenshot is shown in figure 1. Through the comprehensive experiment, the students can understand the basic principles and applications of optical communication simulation, familiar with the use of OptiSystem simulation software, and understand the various methods of dispersion compensation in optical fiber communication system [6].

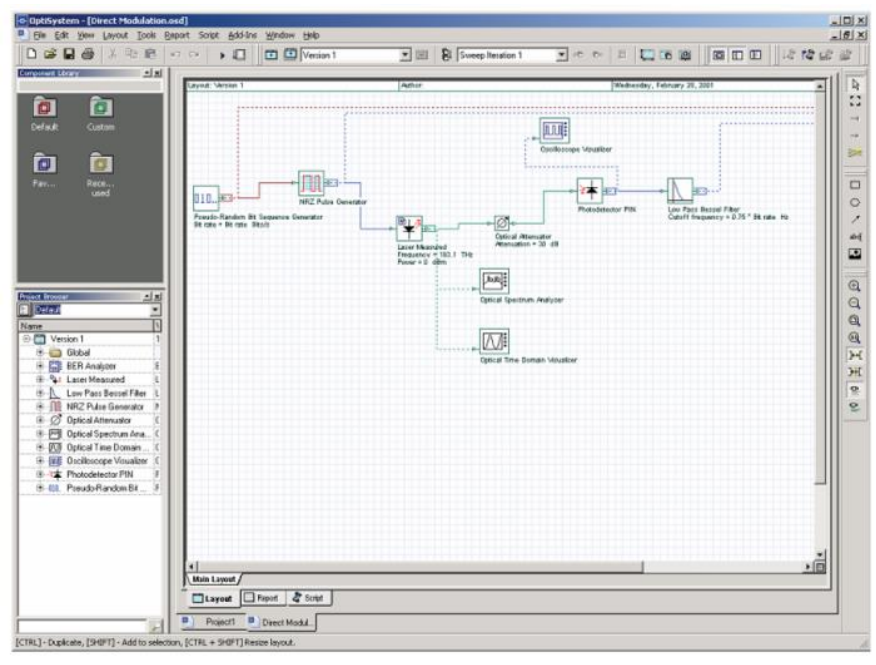

Fig. 1. OptiSystem Modulatioin Sample File

- Encourage team work, and good team is essential for enterprise development. At present the number of classes of optical communication technology and experiment as an example, you need to 3-4 as a team, team to assemble, team group has 1 captain, responsible for coordinating group members, each member should have a division of labor, the performance and contribution of all members of the group leader evaluation scores. 
- To establish a reasonable evaluation system, the initiative and the ability of team or individual strong affirmative, and stressed that the process of evaluation, in the result to be able to reflect the comprehensive design ability, innovation ability and practical ability, to cooperate with enterprises give students extra points.

\section{THE EXPLORATION OF ENTERPRISE ORIENTATION IN COLLEGE STUDENTS' SCIENTIFIC RESEARCH}

\section{A. The characteristics of enterprise oriented scientific research for College Students}

In the training of applied information technology talents, the cultivation of university students' scientific research ability is also indispensable. Of course, it is unlikely to be carried out on a large scale like the teaching process to achieve popularization. But should also be selected by some spare part of the students to carry out the focus of training. In the process of training, we must also pay attention to the characteristics of applied talents, emphasize the orientation of enterprises, and lay a solid foundation for the subsequent employment and employment of students.

After years of research and practice summary, in the enterprise oriented scientific research activities of college students, we must grasp the following basic principles:

- Practicality. To carry out scientific research on the undergraduate level, it is impossible to have too many requirements in theory. On the one hand, students in the undergraduate level of learning in the theoretical foundation is not very solid, on the other hand, especially for application-oriented undergraduate, more attention should be paid to practice. It also has the basic principle of grasping practice, so as to realize the docking with the most extensive enterprises.

- Originality. Today's society is an era of "public entrepreneurship and innovation". Every dynamic enterprise places special emphasis on innovation. Only through innovation can we truly realize the transformation of the economic structure and realize the overtaking in the curve. Therefore, enterprises regard innovation ability as the most important index to inspect the recruitment talents. For applicationoriented undergraduate students, enterprise orientation determines the direction of ability training, therefore, in college students' scientific research activities, we must pay special attention to innovation. Not only in scientific research topics should be innovative, but also in solving the problem of thinking and programs must be innovative in the first place. This requires special guidance from the instructor.

- Feasibility. In many scientific research projects, especially in college students' scientific research projects, a lot of dazzling schemes and innovative ideas are designed, but it is often difficult to achieve. This is often easily understood in the traditional research projects for college students. But in the enterprise, this is totally unacceptable. Therefore, the enterprise oriented college students' scientific research, we must also emphasize the feasibility of the project. No matter how to design the innovation plan, it must be carried out on the feasibility, and the responsible professional quality should be formed.

\section{B. The research project of college students based on "binocular imaging technology vehicle speedometer"}

With the rapid progress of the rapid development of economy and society, city road and highway traffic is more and more complex, at the same time, traffic regulation is increasingly difficult, single rely on manpower to solve is clearly not enough. How to accurately and effectively determine violations, maintain good order, ensure good traffic conditions has become an important issue related to the national economy and the people's livelihood. With the arrival of the intelligent age, the automatic driving of vehicles has become possible, in order to match the intelligent transportation system came into being.

In the intelligent transportation system, more information will be collected by video, and then analyzed and calculated. This project is based on this trend, trying to use binocular imaging, through the construction of dual camera imaging system, video recording of the vehicle. According to the calculation of image processing, three-dimensional coordinates of the vehicle, which can calculate the position and speed of a vehicle and other relevant information, to achieve a flexible speed to maneuver, and at the same time for the access of the intelligent transportation system laid the foundation.

The main content of this project is the measurement of the speed of moving object by binocular imaging system.

The measurement of vehicle speed mainly depends on distance measurement. The distance measurement mainly includes ultrasonic ranging, laser ranging, infrared range finder, ordinary optical ranging and stereo parallax ranging. The first four are active measurement, need to transmit signal; and stereo parallax ranging is passive ranging, no need to transmit signals, good confidentiality, and fast, automatic, real-time, simple device and so on.

Binocular imaging system is to obtain images through two cameras from different angles, or to obtain two digital images from different angles at different times through a single camera [7]. The image obtained after the people, based on the principle of parallax can be recovered 3D geometric information, 3D shape and position information of the surrounding scenery, which can calculate the other required information, such as the speed of moving objects etc. [8]. 


\section{Specific research measures}

This project mainly carries out the binocular imaging ranging work, the main principle is the parallax ranging principle, as shown in figure 2 .

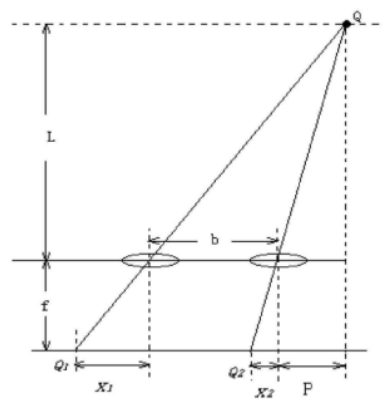

Fig. 2. Parallax Distance Calculation Schematic Diagram

As shown, the two lenses are placed parallel to each other, and the optical axis is B (baseline distance). Q is a point on the object to be measured, the vertical distance to the lens is $\mathrm{L}$, and $F$ is the focal length of the lens. The imaging points on CCD after are Q1 and Q2 respectively, and the distance needed to calculate is calculated by similar triangles in $\mathrm{Q}$ :

$$
L=\frac{b f}{x 1-x 2}
$$

Among them, $\mathrm{x} 1-\mathrm{x} 2$ is the target point, the position difference between $\mathrm{Q}$ imaging on the left and right images, that is parallax, is obtained by image matching; baseline distance b, lens focal length $\mathrm{f}$, are determined by camera calibration. Then the coordinate values of any two points A and B are obtained:

$$
\left\{\begin{array} { l } 
{ X _ { a } = \frac { b x _ { a } } { x _ { a 1 } - x _ { a 2 } } } \\
{ Y _ { a } = \frac { b y _ { a } } { x _ { a 1 } - x _ { a 2 } } } \\
{ Z _ { a } = \frac { b f } { x _ { a 1 } - x _ { a 2 } } }
\end{array} \left\{\begin{array}{l}
X_{b}=\frac{b x_{b}}{x_{b 1}-x_{b 2}} \\
Y_{b}=\frac{b y_{b}}{x_{b 1}-x_{b 2}} \\
Z_{b}=\frac{b f}{x_{b 1}-x_{b 2}}
\end{array}\right.\right.
$$

The actual space distance is:

$$
L=\sqrt{\left(X_{a}-X_{b}\right)^{2}+\left(Y_{a}-Y_{b}\right)^{2}+\left(Z_{a}-Z_{b}\right)^{2}}
$$

$\mathrm{XYZ}$ is the actual coordinate, $\mathrm{XY}$ is the image coordinate, and $\mathrm{B}$ is the baseline distance.

\section{CONCLUSION}

The cultivation of applied information technology talents involves many factors and has a long way to go. The enterprise needs as the starting point for the application of information technology personnel training mode of the preliminary inquiry, that will help to shorten the gap between the real demand of information technology education and the actual effect of enterprise or industry, to help reduce the days after the information technology graduates in the training cost of enterprises after the entry again. At the same time, this paper makes some reflections on how to improve the future professional competitiveness of applied information technology talents, and realize the transformation and upgrading of China's economy to train information technology talents. In order to promote the further development and promotion of information technology specialty in China, it is instructive for the healthy and healthy development of the current applied information technology talents education in china. To promote the further development and promotion of information technology specialty in China, the current application oriented information technology talents education is benign and healthy.

\section{ACKNOWLEDGMENT}

This thesis is supported by the project of "Hangzhou city industry docking project -- special communication engineering specialty construction". This paper also by the Hangzhou City special professional communication engineering construction project "Enterprise oriented reform of optical communication technology and experiment" funding. And the Zhejiang University city academy 2017 annual student research project "Based on binocular imaging velocimetry vehicle" (No. XZ2017522043) funding.

\section{REFERENCES}

[1] W. Li, et al. "Research on enterprise oriented collaborative education model and cooperation mechanism," Journal of Beijing University of Posts and Telecommunications (SOCIAL SCIENCES EDITION), vol. 17(5), pp. 89-95, 2015.

[2] H. Yin, Y. Lv. "Construction of enterprise oriented Applied Undergraduate Practice Teaching System -- Taking Sino German Cooperative Logistics Management Specialty as an example," Applied higher education research vol. 1(4), pp. 57-61, 2016.

[3] T. C. Qi,W. Q. Li, J. Y. Chen. "Construction of enterprise oriented information literacy education system for College Students -- Taking HOLLEY College of Guangdong University of Technology as an example," Management and research of scientific and technological achievements, vol. 7, 2017.

[4] Q. G. Wang, et al. "Application of OptiSystem simulation in Experiment Teaching of optical fiber communication," Journal of Ningbo Polytechnic, vol. 18(1), pp. 26-29, 2015.

[5] X. L. Li. "Application of Optisystem simulation in optical fiber communication teaching," The Science Education Article Collects, vol. 23, pp. 66-67, 2014

[6] J. Xu. " Application of OptiSystem software in the teaching of optical fiber communication technology," Industry and information education , vol. 12, pp. 26-29, 2015.

[7] Z. X. Sun. "Research on distance measurement and velocity measurement of moving object based on binocular vision," Qingdao technological university, 2014

[8] F. B. Liu. " Research on binocular stereo vision distance measurement and speed measurement based on OpenCV," Jilin University, 2012. 